\title{
From a pinch to an open hand: appeals to the evolution of cooperation in contemporary political thought
}

\author{
Dr Joshua Hordern, University Lecturer in Christian Ethics, University of Oxford \\ joshua.hordern@theology.ox.ac.uk \\ Harris Manchester College, Mansfield Road, Oxford, OX1 3TD
}

Keywords: generations, affection, trust, cooperation, institutions, rational self-interest, inheritance, conservatism.

This article considers the political significance of game theoretical notions of cooperation by responding theologically to the writings of David Willetts, a minister in the UK government. The argument is that the forms of cooperative institutional life which societies require can be neither explained nor planned for solely by mathematical modelling of rational selfinterest. What altruistic, civic cooperation depends upon is a complex web of affective trust, often theologically formed by open handed faith rather than a self-protective pinch, so that wise risks may be taken for the sake of future generations.

I am not a scientist, mathematician or philosopher of science and claim no authority in these areas. The argument here concerns political ethics and political theology. Such an engagement signals the wide interest which research in evolution, cooperation and game theory has attracted. This paper will, in particular, explore and evaluate UK government minister David Willetts' use of game theoretical accounts of cooperation. Like Willetts, I have also served as an elected politician, in my capacity as a borough councillor in Bury St Edmunds, a wonderful town which faces challenging questions about the cooperative interrelation of the generations, a keynote of Willetts' thought.

I take 'cooperation' in the sense that Coakley and Nowak have indicated, namely as one party taking a loss or bearing a cost for the sake of a gain or benefit to another party. In cooperation, an individual in a group acts in a way that is costly to the individual but beneficial to another group member. For non-human species, the cost typically concerns genetic inheritance. In the human species, the cost may be genetic but might also entail loss in the cultural realm. A further step made by Coakley and Nowak is to say that, while 'cooperation' may be both a human and a non-human phenomenon, 'altruism' is solely human because altruism requires intentional states.

Willetts is particularly concerned with cooperation between generations. Willetts' book, The Pinch, argues that game theoretical accounts of the evolution of cooperation should shape public policy concerning inter-generational relations. ${ }^{1}$ The thesis there expanded his earlier Oakeshott lecture, Renewing Civic Conservatism, which drew approvingly on Martin Nowak's work. Willetts has also positively reviewed Nowak's book, Supercooperators, for the Financial Times. For Willetts, the blessed generational cohort of 'baby boomers' have failed to bear costs and make sacrifices in order to benefit future generations and instead have kept the benefits of the post-war years to themselves. Although they have, by and large, been decent parents they have not been such good citizens and so the overall political effect of their generation's behaviour has been to undervalue the claims of future generations. Whether or not this trend continues generation by generation will, in towns such as Bury St Edmunds, shape such earthy questions as the development of suitable housing stock and community facilities for an aging population while retaining an integration of the generations in the town's ecosystem. The multiplication of the need for housing nationwide, Willetts

\footnotetext{
${ }^{1}$ Willetts, D., The Pinch: How the baby-boomers took their children's future and why they should give it back, London, Atlantic Books, 2010
} 
observes, is partly due to the break-up of traditional families without any subsequent renewal of the tendency for households to be constituted by couples living with both children and grandparents. ${ }^{2}$ This challenge is an aspect of the larger trend in which the baby-boomers 'have been pinching too big a share of the wealth we are generating now and hope to generate in the future. ${ }^{3}$

\section{Evolution, cooperation and politics}

What, if anything, might game theory, evolution and cooperation teach us about these political challenges? It is common to observe, and Willetts agrees, that people naturally desire both a general story of meaning about human life, however inchoately held, and that this general story should take a political form. In our recent history, evolution has to some extent filled that role as a general story for many people, providing a narrative of human origins. For Willetts, it follows that, in our current political culture in which politicians can no longer appeal effectively to shared moral or theological claims as a basis for public policy, the study of cooperation through the use of game theory has come of age. Game theoretical interpretations of the evolution of cooperation provide a story which is sufficiently compelling to improve our common political life.

Inasmuch as increasing cultural weight is being ascribed to evolutionary explanations of human life as opposed to theological ones, he is perhaps correct - correct that is, about a cultural phenomenon, at least in some parts of those Western countries afflicted by the negative phenomena described in The Pinch. For Willetts, the political virtue of the insights arising from the game theoretical account of cooperation is that their starting point is uncontroversial and acceptable to people apart from any moral or religious commitments. Moreover, what he, as a conservative, finds so promising in Nowak's work is the significance accorded to institutions, especially small institutions in which cooperation is engendered and reputation is at stake:

Nowak has shown that the amount of reciprocity we are willing to undertake with another person is related to the likelihood of our ever seeing them again. The more likely they are to disappear, the less likely we are to help them. So here is the first stage in our process of building altruism. We need to have institutions where people will meet and mingle time and again. If they know for sure that they will see one another, they can engage in more altruism...Institutions are places where people interact with each other sufficiently frequently for co-operation to emerge as a rational strategy. ${ }^{4}$

The question which follows is just what Willetts means here by 'altruism' and 'rational' (in the sense of 'rational self-interest'). At the McDonald symposium in Cambridge in 2011, John Hare commented on the work of Ken Binmore, a writer with whom Willetts is particularly impressed. ${ }^{5}$ Hare notes that 'the notion of self-interest requires reference to motivation' and that Binmore's characteristic error of analysis is displayed in underplaying the distinction between cooperation and altruism. ${ }^{6}$ In an interpretative move which goes beyond the mathematics of game theory, Willetts argues that reciprocity, indexed to rational self-interest, develops the 'trust' which supports altruism not via 'personal moral improvement' but through the exchange of goods, adapting Nowak's interpretation of game theory to argue for cooperation within social institutions, including markets. Not everyone has to cooperate but some must in order that institutions develop which foster

\footnotetext{
2 ibid. 24-34

${ }^{3}$ ibid. 255

4 Willetts, 'Renewing Civic Conservatism', Oakeshott Lecture, available at www2.Ise.ac.uk/publicEvents/pdf/20080220 Willetts.pdf (accessed June 2012)

${ }^{5}$ Willetts, The Pinch, 96-100

${ }^{6}$ Hare, J., 'Evolutionary Theory and Theological Ethics', Studies in Christian Ethics 25.2, May 2012, 244-254, 252-3
} 
empathy, co-operation, altruism and trust. Institutions should therefore seek to conserve what makes for trust in order to 'create their own networks of reciprocity'. ${ }^{7}$

Willetts here draws on elements of moral theory which the mathematics says nothing about namely altruistic motivation and especially affective states such as trust and empathy. ${ }^{8}$ In repeat institutional encounters between people, it is important that they reliably cooperate but even more important - for the sake of cooperation - that they are able to discuss the reasons why they cooperate. Analysis of why cooperation occurs on the motivational level are additional claims which political theorists among others may and, I suggest, must bring to the data. They do not simply come with the mathematical modelling - rather they are interpretations of the findings.

The political stakes for Willetts revolve around how, in the absence of cooperation, the trust deficit which has appeared in the aftermath of baby-boomer success may be overcome. Because of their uncooperative manner of life, there is less intergenerational trust than there should be between them and the next generation. Their reputations are poor, at least outside the immediate circle of their family. Knock-on implications of their behaviour affect, among other things, the (un)availability of affordable housing, income tax revenues, pension plans and levels of 'social trust' in younger generations. Trust which is formed intergenerationally should spread out and permeate civil society, thereby enriching social relationships. Yet Willetts thinks that people today are significantly less likely to trust others than before. ${ }^{9}$

This being said, we are still left wondering what will foster the trust which Willetts believes is so necessary for a cooperative rational strategy to be institutionally effective in establishing and maintaining direct and indirect reciprocity, especially between the generations. The mathematics itself does not deliver an answer to that. Instead it seems likely that answers will come from other sources, such as substantial, meta-ethical commitments. But we have already seen that Willetts is wary of comprehensive accounts of human social flourishing as cultural motors for cooperative behaviour, because any one of them will depend upon claims which are not universally shared. His alternative, surprisingly, seems to be that once people grasp how cooperation works, this understanding itself, combined with an awareness of how generations depend upon each other economically, will give people the kind of motivation towards cooperative behaviour that is necessary for overcoming the 'pinch' which has beset the UK and many Western societies.

\section{Cooperation, institutions and moral theology}

Moral theology should comment on these matters in a manner which takes seriously Willetts' acutely observed concern for improving intergenerational relations in the detail of economic relations. His policy-attuned affirmation of natural, even creaturely, life is an intellectually bracing improvement on what often passes for wisdom in contemporary politics. However, the concerns about trust and motivation require further exploration in order to enrich and recalibrate these insights.

Willetts wants a politics which does not appeal to a substantial account of human nature and certainly not to 'our better natures'.$^{10}$ On the one hand, this marginalisation of metaethics discounts

\footnotetext{
${ }^{7}$ Willetts, The Pinch, 98. Willetts, taking Adam Smith's Wealth of Nations as economic wisdom, links his interpretation of game theoretical accounts of cooperation to Adam Smith's lesser known work, the Theory of Moral Sentiments, and argues that empathy enables the maintenance of our interpersonal political commitments.

${ }^{8}$ Trust is a complex theme but, by my lights, is at least partly affective; cf. Hordern, J., Political Affections: Civic Participation and Moral Theology, OUP, 2012, 239-43, 252-93 esp. 265n50; also Hordern, J., One Nation but Two Cities: Christianity and the Conservative Party, Swindon, Bible Society, 2010, 39-52

${ }^{9}$ Willetts, The Pinch, 120-23; esp. 122 fn23 - data from 1990 Civic Culture in World Values Survey

${ }^{10}$ ibid. 87
} 
a belief in the idea of natural social obligations which he associates with Aquinas and Aristotle. ${ }^{11}$ However, it also discounts a traditional conservative preoccupation with the propensity of humanity to uncooperative behaviour, that distinctively human incapacity to resist what Christian theology has called ' $\sin$ '. In game theoretical terms, many conservatives have believed that the tendency to pursue strategies of defection is an enduring aspect of the human condition which reflects a profound fragility in our capacity for moral stability and moral understanding. ${ }^{12}$ Such an account is too morally comprehensive for Willetts although his scepticism about the capacity of humanity to habituate self-control nonetheless hints in this direction. ${ }^{13}$ Instead, he adopts what he believes are minimal assumptions arising from game theoretical analysis and the universal concern for future generations which he takes to be basic to human societies. So why bother about the future? 'The answer is of course that we are the posterity of previous generations and they did things for us from fighting for us to building schools and churches. ${ }^{14}$ But this answer does not carry so much weight in the argument as the warning that 'we [the older generation] need to behave fairly towards them [the young already born] now so that they will share their bread with us then. ${ }^{15}$ Such cooperation, a cost now for the benefit of a group including oneself, proceeds by rational selfinterest. Such analysis, he believes, does not require any appeal to 'particular religious or ethical assumptions ${ }^{\prime 16}$ but instead depends upon a 'naturalistic account of morality [which, although it] does not resolve all our dilemmas...helps us understand them ${ }^{17}$ since it shows that 'reciprocity...is the origin of our moral sense. ${ }^{18}$

Willetts believes that government should keep a watching brief on patterns of cooperation which develop in society and intervene where appropriate to break some cooperative patterns down and build others up. This is urgent since institutions can reach such a state of undesirable cooperation that revivification is impossible. ${ }^{19}$ Willetts believes that we 'cannot just offer freedom, opportunity and choice without also recognising the power of belonging, commitment and roots.' Then the question becomes 'how do we find a way to explain these obligations in a society less susceptible to appeals to tradition or religion? ${ }^{20}$ His answer is that altruistic obligation will arise by means of an inner structure of humanity according to game theoretical patterns whereby enlightened selfinterest achieves cooperative equilibria through repeat direct reciprocal encounters and the reputation developed through those encounters. This 'is how institutions and incentives work'. Accordingly, 'ingenuity in designing an institution creates 'trust'. We do not need to rely on personal moral improvement, desirable though that would be, nor worry that we are somehow worse people

\footnotetext{
${ }^{11}$ ibid. $88 \mathrm{fn} 10$

${ }^{12}$ Cf. Quinton, A., The Politics of Imperfection: The Religious and Secular Traditions of Conservative thought in England from Hooker to Oakeshott, Faber and Faber, 1978

${ }^{13}$ Willetts, The Pinch, 149

14 Ibid. 145

${ }^{15}$ ibid. 146

16 ibid. 88

17 ibid. 101

18 ibid. 263

${ }^{19}$ Willetts, 'Renewing Civic Conservatism', 10-11. He appeals particularly to two examples, the first being the cooperation of German and allied soldiers at the front who were willing to fire over each other's heads rather than shoot to kill. The generals should break up this kind of cooperation. The other example is competition (anti-trust) law which combats, he claims, the kind of 'cooperation' between companies which society does not want. Whether competition law combats what is technically 'cooperation' or actually fights 'collaboration' seems important here since cooperation is, by Nowak and Coakley's definition, altruistic, bearing a cost to self for the sake of a benefit to another. Surely competition law is not about that.

20 'The invisible hand that binds us all', Review of Supercooperators, Financial Times, April 242011 , http://www.ft.com/intl/cms/s/2/f3e5965e-6e9a-11e0-a13b-00144feabdc0.html\#axzz1yKUW5SYI
} 
than we were. We need to give institutions the space to emerge and to function and create their own networks of reciprocity. ${ }^{21}$

Such an approach contrasts markedly with Margaret Thatcher's Christian beliefs evidenced in her remarkable 'Sermon on the Mound' at New College in Edinburgh. For Thatcher, if 'you try to take the fruits of Christianity without its roots, the fruits wither. And they will not come again unless you nurture the roots. ${ }^{22}$ This is very much a case, then, of Willetts vs. Thatcher on a point of the most profound principle. Be that as it may, Willetts' insight seems plausible on one level at least: institutions will be healthier where people decide against the 'always-defect' strategy and prefer cooperation in service of the common good. Granted that all want to see altruistic sacrifice from one generation to the next, the issue is how this will come about. My observation is that Willetts has given an insufficient explanation for the development of altruistic cooperative institutions since altruism and trust are further factors in institutions which are not explained by mathematical modelling. For example, Willetts notes that the British people's religion and religious institutions are part of our inheritance but has no place for religion in the development of trust. He rightly reclaims 'social contract' language from an abstract, individualistic usage which undermines intergenerational thinking in order to restore a Burkean insight of the moral unity of the dead, living and unborn. But, following Hume, he seeks a 'naturalistic account of society and morality' and contrasts this with 'appeals to external or ethical obligation which appear to solve tricky problems by some deus ex machina. ${ }^{23}$ Theology uses such 'sky-hooks', Willetts claims, and are inadmissible in contemporary policy thinking. Such marginalisation of various traditions of religious thought is consonant with his view that substantial moral or religious claims will not gain widespread support in contemporary plural British society.

The proposal that evidence-based policy must be central to the work of government deserves warm support but Willetts' account of theological ethics as dei ex machina for tricky moments is puzzling. It is certainly an aspect of Christian political thought that God will unexpectedly return like a thief in the night or a bridegroom to a wedding party. But this eschatological expectation actually energises and guides activity in the present throughout every kind of societal institution and interaction. Theology is not just for the tricky moments nor does it simply come in 'at the end'. To describe theological ethics like this underplays its significance in social institutions. Moreover, if Coakley and Nowak are right, it ignores a very promising way of gaining those insights into the human condition which drive the research into the evolution of cooperation on which Willetts' public policy proposals depend.

In any case, ethics - including theological ethics - has more significance than Willetts allows. For ethics presses politicians to reflect on the substantial political question, namely that, if we agree that cooperation, in its human altruistic form, can be fostered, can this be done by appealing to game theoretical accounts of evolutionary theory alone? This question refines the concern already mentioned namely that Willetts, despite his disavowal of any claim to depend upon our good natures, is in fact more optimistic about the ingenuity of government and the stability of rational self-interest than he indicates. This would explain why Willetts place 'trust' in inverted commas ${ }^{24}$ because his theory depends upon it arising as part of the mechanism of ingeniously arranged institutions rather than as a further moral factor which may or may not arise depending on additional 'external' influences on the people who participate in institutions. Such 'external' influences might include substantial moral or religious commitments.

\footnotetext{
${ }^{21}$ Willetts, The Pinch, 97-98

22 Speech to the General Assembly of the Church of Scotland, May 21, 1988, accessible at www.margaretthatcher.org/document/107246

${ }^{23}$ Willetts, The Pinch, 86

${ }^{24}$ Cf. fn21
} 
The problem is that explaining that institutions may function according to the mathematical modelling uncovered by Nowak et al. is no sure sign that they will so function. If this distinction is allowed, then it is difficult to discern just what Willetts' practical policy proposal might be. If the cooperative patterns that game theory describes do not happen on their own but in fact require appropriate moral conditions, then Willetts' avowed intent to seek an account of human nature with minimal assumptions seems wrongly focussed. The really interesting question concerns what moral features characterise those institutions which exhibit marked levels of stable cooperation. In a polity where many visions of the good (and of God) compete with one another in robust but hopefully peaceful dialogue, the people's concern for posterity will be motivated by a significant diversity of reasons with which politicians must reckon rather than rule out. This is not 'about pouring social cement over atomized citizens ${ }^{\prime 25}$ but rather a properly conservative attention to the moral commitments of the people whom government serves. This seems more reasonable and democratic than the dual assumption against the goodness of human nature and in favour of the idea that rational self-interest organised in institutions will somehow yield altruistic, cooperative people who learn to value their reputation more than short-term gain through defection.

If this is so, then the important, practical questions concern the manner in which substantial moral and theological accounts should enrich the public understanding of human society and of the cooperative patterns which lie therein. In a polity of many moral and theological viewpoints such as the United Kingdom, there needs to be an ongoing public debate as to which meta-ethical theory or theories both effectively fit the evidence provided by game theoretical accounts of cooperation and provide resources to explain and enrich human motivation in pro-social ways in the myriad forms of institutional interaction, including the many that game theory will find it hard or impossible to model. There is, therefore, an inescapable contest about ultimate human meaning which statesmen and stateswomen should neither fear nor shirk but rather should enter into, alongside all the rest of us, with the fear and trembling appropriate to their office.

A Christian contribution to the debate would be guided by how the doctrines of creation and sin are correlated to evidence of group evolution and, moreover, the significance of the cross and resurrection as the core definition of God's saving activities amidst the deep structure of created life. The implication of Nowak and Coakley's view is that the resources of Christianity can contribute distinctively to the growth of trust in both local and national settings. Whether or not they are more hopeful than they ought to be about the apologetic power of their particular claims - and opinion is divided on this - there remains the substantial political question about what ideas will fuel the kind of reweaving of the generations that Willetts rightly identifies as a vital indicator of social health. Nostalgia is not a practical policy position. Nonetheless, Christian institutions and institutions influenced by Christianity are features of British civic life which are effectively contributing to the development of cooperation. As such they may give content to and indeed critique political ideas such as the 'Big Society'. Willetts comments that the 'Government has a role in helping to create the conditions in which co-operation will flourish and it must break down co-operation which it does not think is good. This is a political judgement which sometimes comes down to normative values' ${ }^{26}$ However, this recognition of normativity, though welcome, does not exercise sufficient control of the argument in The Pinch. In any case, such remarks simply invite the question of which normative values we are talking about. The purpose of this symposium is to make normative metaethical discernments as to what account of reality does justice best to game theoretical analysis and, moreover, which does best justice to the affective concomitants of meta-ethical theories, especially those which concern 'trust'.

\section{From a pinch to an open hand?}

\footnotetext{
25 ibid. 98

${ }^{26}$ Willetts, 'Renewing Civic Conservatism', 11
} 
A further welcome feature of Willetts' book is that he looks, despite his disavowal, for corroborative evidence of intergenerational concern in various traditions of moral thought. In reference to the fifth commandment to honour one's father and mother, Willetts recognises that 'even the Bible is implying some kind of reciprocity between the generations' and suggests that this is 'an exception for the intergenerational contract in the otherwise unconditional structure of the Ten Commandments' ${ }^{\prime 27}$ which, if 'they say anything about consequences, they are in the next world not this one. ${ }^{28}$

Whilst Willetts' admiration for the fifth commandment is welcome, his analysis is not a fair assessment of the way that the moral reasoning of the Mosaic law operates, let alone the rest of the Jewish and Christian Scriptures. This is unfortunate since he has already confidently set aside the beneficial influence of religious moral reasoning as depending on 'sky-hooks' and therefore as unable to exercise a beneficial public effect on a plural society's discourse and practice. Accordingly, to address this lacuna, I turn to consider how these Scriptures might yield just the wisdom which is necessary for a fruitful political engagement with apparent discoveries about the evolution of cooperation.

Contrary to Willetts' exposition, all the ten commandments and the many others of the Jewish Scriptures are set within a narrative, are dependent upon just the kind of institutions and intergenerational thinking which Willetts applauds and have a this-worldly significance which is, in the Christian vision at least, only deepened and sharpened by the promise of the new world to come. The provisions of Moses' law and Christ's fulfilment of them in fact stimulate just the regard for futurity which Willetts recognises is missing from contemporary Britain's vain search for happiness in a consumer culture which, in the absence of long-term vision, encourages people to disregard sacrificial relationships. ${ }^{29}$

The Christian inheritors of Israelite institutions attest their fulfilment in Jesus of Nazareth and their transformation, by the power of the Holy Spirit, into the global phenomenon of local churches and the myriad institutions to which such churches gave birth. Churches can be 'uncooperative' in the loose sense of resisting government policies. The current Conservative-Liberal coalition knows this all too well. But churches and the many institutions that arise through Christian faith act as incubators for the kind of questions which this symposium is about. One reason for this lies in the Jewish Torah, inherited by Christianity, where we find the repeated theme of the 'open hand'. In Deuteronomy, we read 'If among you, one of your brothers should become poor, in any of your towns within your land that the LORD your God is giving you, you shall not harden your heart or shut your hand against your poor brother.' Instead, Moses says, 'I command you to be open-handed towards your brothers and towards the poor and needy in your land.' (Deuteronomy 15:7, 11)

The premise of Moses' summons to open-handedness is the logic of inheritance: that the land the people possess is a gift from God to be passed on generation to generation in good repair and without selfish grasping. The focus on 'brotherhood' recalls the familial pattern of Israel's life which, extends from extended, localised family networks to tribal and national levels. This familial and multi-tribal pattern is then reshaped by the New Testament people of God as a vision for universal, global humanity and rooted in many local institutions whereby the local church gather to serve their neighbours, including (of course!) those who are not Christians. Each person is a brother or sister with whom trusting relationships may be built. The inheritance is no longer a particular land but

\footnotetext{
${ }^{27}$ Willetts, The Pinch, 109

28 ibid. 104

${ }^{29}$ ibid. 150, 29
} 
rather all the earth which is to be conserved and shared in a manner which serves not only the living but those yet unborn. ${ }^{30}$

This wisdom of this social vision has the capacity to turn whole peoples and civilisations from a pinch to an open hand. The institutions of the Jewish and Christian traditions have traditionally brought civilisation-shaping energy while, at the same time, enabling followers of Christ to retain their own internal, communal integrity as those who bear witness to the God who orders human relationships. But, in describing such traditions as only fleetingly attuned to intergenerational concern, Willetts overlooks just the resources which could provide the trust that cooperative institutions require. To believe that to change a generation's commitments one can appeal to the insights of game theory to the exclusion of theology is to risk crippling aspects of one's public policy. It will certainly not be an account that 'reaches across the different religious or ethical views' of the UK. ${ }^{31}$ Rather, the marginalisation of profound moral or religious motivation runs the risk of throwing the baby out with the previous generation's bathwater.

For the incarnation of Christ, in fulfilment of Israel's institutions, has exercised a profoundly important and beneficial shaping influence on the institutions of the United Kingdom and continues to do so today. Thankfully, it is the logic of Willetts' book that, in addition to criticising malign aspects of traditions, including religious traditions, such as an obscurantist scepticism about the insights of natural and social sciences, we should have regard for the wisdom of previous generations. Accordingly, it should be welcome news that the moral vision that Christ's gospel bestowed upon humanity is the motor which is powering innovative new insights into the evolution of cooperation. ${ }^{32}$ More decisively, though, Christian wisdom provides the hope which, being quite distinct from optimism about ingenuity in institutional design, should take people forward into growing relations of trust and risk. Since Christians' lives are already guaranteed by Christ, they may take the risk of inter-generational love, confident of their reward because of the grace of God. The guarantee of life with Christ in the new heaven and the new earth frees Christians not to grasp at the goods which should properly be bequeathed with an open hand to familial heirs and civic successors. It frees them to ensure that the world is passed on to their children and their neighbours' children in as good a state as possible because the self-obsessed desire to rape it for one's own advantage alone is overcome by the loving promises of God. Love and self-love are not opposites in Christ's kingdom but, properly understood, are the moving parts of the second command of Christ whereby one's own future condition, both in this life and the next, is intertwined with the regard one has for one's living and unborn neighbours. But note especially that the logic of inheritance holds whether or not one requires support from the younger generation in one's old age. For this is a vision which seeks the common good beyond one's own death, the good for children's children and forevermore.

Ultimately, this logic is dependent on the resurrection of Christ from the dead which, far from making people so heavenly minded as to be no earthly good, acts as the horizon towards which humanity are summoned to walk, doing earthly good as they proceed. Unfortunately Willetts marginalises the way that Christian thought and practice has shaped our common life in the United Kingdom. This is regrettable since it would strengthen and recalibrate his argument in favour of intergenerational bonds of trust, commitment and affection. The future of theological ethics lies partly in preaching and teaching Christ's way of life whereby people adopt a risk-taking commitment to futurity - both for this age and the one to come - which is funded by the gifts of faith and love that spring from the coming hope stored up for us by God's grace (Colossians 1:5).

\footnotetext{
30 For a peculiarly British conservative reflection of this concern, see Scruton. R., England: an Elegy, Continuum, 2006, 119; cf. Hordern, J., Politcal Affections, 239-43

${ }^{31}$ Willetts, The Pinch, 101

${ }^{32}$ Coakley, S., 'Response to John Hare', Studies in Christian Ethics 25.2, May 2012, 255-260, 258
} 
Willetts hints at this logic when he comments that the 'key issue in our ability to control ourselves may be connectedness - the links between us now and how we think we could be in the future.' He rightly says that 'if you [lack] an authority figure you trusted to do things for you in the future you [find] it much harder to have your own plans for the future and make sacrifices for them. ${ }^{33}$ What may be true of earthly fathers is certainly true of the heavenly Father. When Willetts calls for 'an environment rich in commitment devices [which] includes institutions with long and stable histories where we can be confident of rewards and indeed penalties out into the future ${ }^{34}$ he perhaps should be heard as inviting, albeit indirectly, those commonly marginalised traditional religious and moral viewpoints to play a more robust part in UK national life.

\section{Conclusion}

So can a bald understanding of evolutionary interpretations of game theory either account for or ensure altruistic cooperation either on the societal level or as a guide to government policy? It seems not and I submit that this is a serious problem for Willetts' otherwise praiseworthy concern for intergenerational obligations. But may the Christian people, inspired by a vision exposited from Scripture and appropriately informed by natural and social science, be those who love their neighbours as themselves in a fashion which stimulates and guides cooperative institutions which do have regard for posterity? And may all people, whether or not they name Christ as Lord, share in that wisdom, however obliquely? It seems so and this is a vision which offers to bind up the generations and heal those wounds to which government, on its own and however ingenious, will always be inadequate.

In There is Such a Thing as Society, a book of essays which galvanised the work of lain Duncan Smith and which David Willetts generously supported, there is extensive recognition of the role of Christian faith in opening people's hands that they might be willing to bear a cost for the sake of a benefit to another. ${ }^{35}$ This seems to me common ground on which a regard for posterity can be established. But the practical policy implications is that political representatives must understand the people they represent in ways which summon those same people to seek the common good which they already have in mind to achieve. Whether it is housing in Bury St Edmunds, the transfer of community facilities to church-led local community control, pension plans for those entering the labour market or the role of arts and humanities disciplines such as theology in contemporary universities, the need for such long-term thinking requires not fewer public partnerships between government and people of faith but more and more nuanced ones. A proper regard for Christian faith and indeed the distinctive visions of other faiths will be vital for dealing with the present and coming crises both in the UK and on the international level where religious faith very reasonably shows no sign of giving up its search for wiser responses to the challenges of the twenty-first century than the secularised West has so far offered. ${ }^{36}$

\footnotetext{
${ }^{33}$ Willetts, The Pinch, 151

34 ibid. 152

${ }^{35}$ Streeter, G. (ed), There is Such a Thing as Society, Politico's Publishing, 2002

${ }^{36}$ Willetts, The Pinch, 258
} 